\title{
Educação Ambiental e os Gêneros Textuais
}

\begin{abstract}
Maria do Carmo Leite de Oliveira ${ }^{1}$
Resumo: Este artigo apresenta uma articulação entre a disciplina transversal, Meio Ambiente sob a ótica do estudo dos gêneros textuais nas aulas de Língua Portuguesa, a pesquisa em questão envolveu uma sala de aula de $7^{\circ}$ ano, fundamental II , de uma escola pública municipal da cidade de Juazeiro do Norte Ceará. Esse estudo propôs um breve referencial teórico sobre a tipologia textual, gêneros textuais, meio ambiente e a educação ambiental. Através dessa pesquisa percebeu-se que os temas transversais raramente é discutido e abordado no interior dos ambientes escolares, o que de certa forma, nota-se que a maioria dos docentes ainda se restringem apenas a área específica na qual lecionam, não dando ênfase a integração entre as outras disciplinas, ou seja não articulam ou propõem a interdisciplinaridade entre as outras áreas do saber. Foi relevante também através desse trabalho que os discentes participaram com afinco, de maneira satisfatória, no decorrer de todo o estudo, o que se constatou que a interdisciplinaridade é um "pilar" a ser construído e ampliado nas salas de aula.
\end{abstract}

Palavras-chave: Educação ambiental, meio ambiente, tipologia textual, gêneros textuais, interdisciplinaridade

\section{Environmental Education and Texts Genrers}

\begin{abstract}
This article provides a link between the cross-discipline Environment from the perspective of study of genres in Portuguese classes, the research in question involved a classroom 7th grade, elementary II, a public school in the city of Juazeiro do Norte, Ceará. This study proposed a brief theoretical framework on the textual type, textual genres, environment and education environmental. Through this research it was observed that the cross-cutting issues is rarely discussed and addressed in within the school environment, which in a way, it is noted that most teachers still restricted only the specific area in which they teach, not emphasizing the integration of other disciplines, that is not articulate or propose interdisciplinarity among other areas of knowledge. It was also relevant through this work that the students participated diligently in a satisfactory way in the course of the entire study, which It found that interdisciplinarity is a "pillar" to be built and expanded in classrooms.
\end{abstract}

Keywords: Environmental education, environment, textual type, textual genres, interdisciplinarity.

\section{Introdução}

A educação ambiental é uma das questões que mais vem sendo debatidas no mundo, seja através de jornais, revistas, internet, mídias de uma maneira geral etc, as escolas também, que tem grande poder como formadora de opinião, já se atentam para esse compromisso que se tornou global.

\footnotetext{
${ }^{1}$ Mestranda na Anne Sullivan University. E-mail: carmem_leite63@ hotmail.com
} 
Isso se deve aos enormes prejuízos que o meio ambiente tem sofrido ao longo dos anos por decorrência da ambição humana. Sendo assim, esse estudo tentará relacionar as questões ambientais de forma a conscientizar, discutir e compreender como podemos reverter o quadro do desgaste natural tão discutido, já que os recursos naturais estão escasseados, por ter sido usados de forma abusiva, desregrada (sem consciência humana).

Sabe-se que os educadores tem um grande poder na formação cidadã dos educandos, o que podem disseminar logo nos primeiros anos, a partir do ingresso da criança na escola como essa agirá em relação a natureza, mostrando que o homem necessita dela para a sobrevivência. As futuras gerações poderão ser multiplicadoras dessa consciência de preservação ambiental na sociedade inserida.

\begin{abstract}
Nesse sentido, as situações de ensino devem se organizar de forma a proporcionar oportunidades para que o aluno possa utilizar o conhecimento sobre o meio ambiente para compreender sua realidade e atuar sobre ela. $\mathrm{O}$ exercício da participação em diferentes instâncias (desde atividades dentro da própria escola, até movimentos mais amplos referentes a problemas da comunidade) é também fundamental para que os alunos possam contextualizar o que foi aprendido (BRASIL, 2001, p.48).
\end{abstract}

Em relação aos gêneros textuais tão abordados nas aulas de Língua Portuguesa, esses servirão de base para discussão, compreensão e mudança de atitude na busca por um ambiente mais saudável, menos poluído e devastado, já que os vários materiais textuais são utilizados diariamente nessa disciplina, o que se mostra de certa forma uma abertura para o questionamento de um tema tão grandioso e de relevância, não só para o futuro do planeta, mas para o hoje, pois já se percebe a extinção de recursos naturais essenciais para a sobrevivência da humanidade.

Para a concretização desse trabalho foi realizada uma pesquisa bibliográfica sobre a Educação Ambiental e os Gêneros Textuais, e também se realizou uma pesquisa de campo com uma sala de $7^{\circ}$ Ano de uma escola pública municipal de Juazeiro do Norte. Nessa pesquisa se observa a importância da Língua Portuguesa com esse tema, mostrando que através dos gêneros textuais pode-se fazer a contextualização sobre esse assunto que merece destaque, a fim de que os discentes possam discutir, pesquisar e produzirem textos nos mais diversos gêneros enfatizando os problemas ambientais, as consequências já vistas por descaso da humanidade, e o que ainda se pode fazer para amenizar os prejuízos, fazendo-os se 
Id on Line Revista Multidisciplinar e de Psicologia

Id on Line Multidisciplinary and Psycology Journal

conscientizarem da conservação da natureza, somente essas futuras gerações poderão disseminar essa ideia que se tenta evidenciar.

\title{
Os Gêneros Textuais
}

Pretende-se com esse estudo interdisciplinar possibilitar a integração desses dois temas tão relevantes nas áreas do currículo escolar, tentar que haja a reflexão sobre a educação ambiental e estudar os gêneros textuais tão mencionadas nas aulas de Língua Portuguesa.

É do conhecimento de todos que a disciplina de Língua Portuguesa é aberta para a interação em todas as áreas do conhecimento, buscando de maneira notória o envolvimento, a ligação com as demais formas de erudição. Essa proposta interdisciplinar mostra que não é impossível interagir uma disciplina com outra, na qual muitos docentes ainda precisam progredir em relação a essa questão, percebendo que é importante essa articulação nas práticas educativas.

\begin{abstract}
A sensibilidade e a competência do professor em estabelecer tais pontes, levando em consideração a rede de significações preexistente no universo dos alunos, aproximam seu trabalho efetivamente de uma dimensão poética, que sobrepuja os aspectos meramente técnicos de seu fazer, se uma imagem vale mais do que mil palavras justamente porque pode promover articulações que somente muitas palavras podem lograr, uma proporção analógica, como um poema em ponto pequeno, pode articular inúmeras imagens, inspirando conexões muitas vezes inesperadas (MACHADO 2011, p.157).
\end{abstract}

Nessa perspectiva procura-se abordar um pouco sobre os gêneros textuais e sua importância na disciplina de Língua Portuguesa. De acordo com alguns dicionários a palavra texto é um conjunto de palavras e frases encadeadas que permitem interpretação e transmitem uma mensagem. KLEIMAN E MORÃES (1999:62)

Texto (do latim textos, tecido) é toda construção cultural que adquire um significado devido a um sistema de códigos e convenções. Ao se tratar de gêneros textuais, esses podem ser definidos como as estruturas com que se compõem os textos, sejam eles orais ou escritos. Essas estruturas são reconhecidas socialmente e estabelecem formas próprias de organização do discurso, sendo de natureza sociocultural manifestam-se através das diversas situações comunicativas. 
Id on Line Revista Multidisciplinar e de Psicologia

Id on Line Multidisciplinary and Psycology Journal

Segundo Porto (2009, p.38),

O ensino dos diversos gêneros textuais que circulam socialmente não só amplia sobremaneira a competência linguística e discursiva dos alunos, mas também aponta-lhes as inúmeras formas de participação social que eles, como cidadãos, podem ter fazendo uso da linguagem.

Fazendo um breve histórico sobre os gêneros textuais, os mesmos surgem como necessidades socioculturais e como inovação tecnológica, já que hoje existem diferentes gêneros textuais se comparados as sociedades antigas, isso se deve principalmente ao código verbal, a escrita.

Analisando a história dos gêneros textuais, esses se manifestam de início de forma lenta, apenas na linguagem oral, isto é, haviam poucos gêneros, o que para a época era suficiente, com a invenção da escrita alfabética os mesmos começaram a serem ampliados, o que já não eram mais limitados. Entre os séculos XV e XVIII os gêneros textuais tornam-se dada vez mais acessíveis, isso é justificado pelo aparecimento da cultura impressa e pelo início da industrialização, o que intensificou a expansão dos mesmos.

Hoje em meio a cultura tecnológica ou eletrônica , na qual a internet e porque não falar também do predomínio das redes sociais, o mundo se tornou globalizado, o que se observa constantemente mais gêneros textuais e novas formas de comunicação tanto verbal como não-verbal surgindo.

A população está preocupada mais na comunicação sociocultural de que com os aspectos linguísticos propriamente ditos, na atualidade o que prevalece é se o interlocutor entende a mensagem, e não os aspectos linguísticos, gramaticais que essa foi elaborada. Assim os gêneros textuais se integram cada vez mais a sociedade.

\section{Tipologia Textual e Gênero Textual}

Observando os estudos de MARCUSCHI, esse mostra que seria impossível se comunicar verbalmente, a não ser por gênero textual, assim como é impossível se comunicar verbalmente a não ser por um texto. Os gêneros textuais são os diversos textos que se 
Id on Line Revista Multidisciplinar e de Psicoloqia

Id on Line Multidisciplinary and Psycology Journal

encontram na forma material para explicar a vida em sociedade aos quais apresentam aspectos sócio-comunicativos (MATTA 2009, p.104). O autor nos orienta que,

É nesse aspecto que a atividade de textos realmente se realiza e ganha identidade, pois, em função das diferentes situações de uso, os enunciados vão sendo organizados, agrupados, de acordo com a finalidade a que se propõem. Desenvolver essa competência comunicativa é fundamental, pois transgredir além de certos limites da convenção estabelecida socialmente para a organização e apresentação de um texto pode significar a rejeição desse mesmo texto nos meios em que ele deveria circular( da mesma forma que não vai a um casamento de pijamas).

A tipologia textual é limitada, o que se estuda na disciplina de Língua Portuguesa são o descritivo, o narrativo, o expositivo, o argumentativo e o injuntivo, cada um com suas especificações, enquanto que os gêneros textuais existem uma infinidade, como exemplo se tem carta comercial, novela, teatro, noticia, horóscopo, bula de remédio, resenha, bilhete, biografia, bate-papo por computador ou mais recente pelo celular, aula expositiva, romance, conto etc.

Vale lembrar que a expressão "tipo textual", muito usada nos livros didáticos e no nosso dia a dia está empregado de maneira errônea, e não designa de um "tipo", porém de um gênero de "texto". Por exemplo quando se apresenta ao aluno um conto, se diz, esse é um tipo de texto, o que a maneira como o docente aborda está equivocada "tipo de texto", na verdade precisa-se dizer que o "conto" é um gênero textual da tipologia narrativa, o que torna mais completo o entendimento do discente em saber diferenciar tipologia de gênero textual.

Vale lembrar ainda que um mesmo texto ou gênero textual pode conter mais de uma tipologia, por exemplo: Ao se enviar uma carta, essa sendo pessoal, a mesma conterá trechos narrativos, contando fatos, situações, o que a pessoa tem feito; descritivo, quando se descreve um lugar, um objeto, uma pessoa etc; argumentativo, se se defende alguma ideia, entre outros.

Enfim, cada situação comunicativa social exige uma forma de linguagem diferente, específica, fala-se e escreve-se de acordo com a situação social que é estabelecida em determinado momento, assim são os gêneros textuais, os mesmos vão se agregando socialmente atentando-se para os diversos tipos ou usos da linguagem. 
Id on Line Revista Multidisciplinar e de Psicologia

Id on Line Multidisciplinary and Psycology Journal

\title{
A Educação Ambiental, Meio Ambiente e Desenvolvimento Sustentável
}

Sabe-se que hoje a questão ambiental vem sendo discutida e considerada como urgência para a sociedade, pois a mesma está comprometida devido ao desgaste em excesso que o homem a explorou e o futuro do planeta depende cada vez mais de estratégias e ações que possam reverter a realidade.

Como já é de conhecimento de uma grande maioria da população mundial, a sociedade relacionada a natureza se tornou "relação de mercado", isto é, quanto mais se desmata, se queima, se planta etc, tudo irá passar a ser lucro nas mãos de grandes empresários que só veem o capital em primeiro plano, não questionando sobre os danos causados ao ambiente, porém todas essas ações destruidoras à natureza acarretaram enormes prejuízos para os humanos, o que esse questionamento se leva a repensar sobre como manter o capitalismo sem causar mais danos a essa.

Observa-se que nos últimos séculos a industrialização se tornou o principal alvo desse lucro desenfreado, com sua forma de produção de trabalho, mecanização da agricultura, intensivo uso de agrotóxicos etc, então, nessa perspectiva a tecnologia evolui muito rápido, gerando também destruição mais agressiva ao nosso bioma, com isso os recursos naturais estão se escasseando, e pouco se faz para que essa ameaça se amenize.

\begin{abstract}
A demanda global dos recursos naturais deriva de uma formação econômica cuja base é a produção e o consumo em larga escala. A logica, associada a essa formação, que rege o processo de exploração da natureza hoje, é responsável por boa parte da destruição dos recursos naturais e é criadora de necessidades que exigem, para a sua própria manutenção, um crescimento sem fim de demandas quantitativas e qualitativas desses recursos (BRASIL, 1998, p.173).
\end{abstract}

Percebe-se que após a industrialização ou do uso dos mais diversos avanços tecnológicos se acelerou a exploração dos recursos naturais pondo em risco toda a renovabilidade dos mesmos, o que antes se retirava uma árvore, agora desmata centenas de uma só vez, sem se falar no número de habitantes que aumentaram ao longo dos anos, na qual esse aumento se precisará devastar mais desse bioma na construção de mais moradias, consumir mais água dos rios para uso entre outros.

A partir desse acelerado desenvolvimento se observa os grandes efeitos negativos para a saúde do planeta, tanto para a humanidade, quanto para os reinos vegetal e animal. Nesse 
Id on Line Revista Multidisciplinar e de Psicoloqia

Id on Line Multidisciplinary and Psycology Journal

sentido foi iniciado a preocupação com o meio ambiente, mobilizando vários países em busca de uma solução rápida para um problema gigantesco. Sendo assim se iniciou o engajamento em torno desse olhar ao meio ambiente a partir desse momento, em que a saúde física e psicológica da população urbana estava sofrendo efeitos negativos, na qual estudos comprovaram que tudo que se retira do bioma natural afeta a todo o ecossistema.

\begin{abstract}
Após a Segunda Guerra Mundial, principalmente a partir da década de 60 , intensificou-se a percepção de que a humanidade pode caminhar aceleradamente para o esgotamento ou a inviabilização de recursos indispensáveis a sua própria sobrevivência. E assim sendo, que algo deveria ser feito para alterar as formas de ocupação do planeta estabelecidas pela cultura dominante (BRASIL, 2001, P.21)..
\end{abstract}

Um outro fator relevante que merece se dar ênfase é o êxodo rural, fazendo essa população procurar a cidade por acreditar que a zona urbana terão mais qualidade de vida, isto é, nutrem-se que terão mais chances de emprego, escolas mais preparadas para os filhos, redes de saúde próximos etc, porém a degradação ambiental se potencializa com um auto fluxo de urbanização, destruindo a natureza sem conhecimentos especializados o que gera mis impactos ao meio natural.

Somente na metade do século XX, como já citamos anteriormente, é que ecologistas se unem e se organizam para a realização de um movimento ambientalista, tudo é iniciado primeiramente com a proposta de preservar as áreas naturais intocadas pelo homem, chamadas hoje Parques Nacionais.

Sabe-se de acordo com os estudos ecológicos que uma pequena degradação em um local afeta não só aquele local, mas amplas regiões e pode ultrapassar para outros países. Um caso bem recente que merece ser citado, que ocorreu no Brasil e ganhou repercussão no mundo inteiro foi o rompimento das barragens na cidade de Mariana (MG), hoje é considerado um dos maiores desastres ambientais do Brasil e do mundo, as barragens continham lama resultante do rejeito da produção de minério de ferro de uma empresa de mineração do país. Essa tragédia teve e terá impactos ambientais exorbitantes, sem contar que a população da cidade que habitava próxima a empresa ficaram desabrigadas, e os rejeitos de lama contaminou as águas do Rio Doce, essa chegando ao mar.

As consequências foram muitas, morte de pessoas, animais terrestres e aquáticos, sem se falar na destruição do bioma. Com esse desastre se tem certeza que a degradação do meio ambiente não terá consequências negativas apenas para aquele município ou região , não 
Id on Line Revista Multidisciplinar e de Psicoloqia

Id on Line Multidisciplinary and Psycology Journal

muito distante esses efeitos através da correnteza da água ultrapassará o país, incluindo assim efeitos nocivos a todo o planeta.

Se um país resolver fazer um experimento atômico, o mundo todo sofre, em maior ou menor grau, as consequências dessa ação. Um desastre numa usina nuclear atinge, num primeiro momento, apenas o que está mais próximo: pessoas, alimentos e todas as formas de vida. Num segundo momento, pelas correntes da água, pelos ventos e pelas teias alimentares, dentre outros processos, o desastre pode chegar a qualquer parte do mundo (BRASIL, 1998, P.176)..

Dessa forma o mundo se reúne para debater o que pode ser feito para reverter esse quadro que se tornou de urgência: O meio ambiente precisa de ajuda, dele depende o futuro das nações. Se de um lado a "globalização econômica" se expande cada vez mais, do outro é lamentável o agravamento dos problemas ambientais, isso obrigou a sociedade de um modo geral impor regras a exploração desenfreada, ao crescimento e como é possível gerir melhor a distribuição dos recursos naturais, equilibrando e garantindo a todos uma melhor qualidade de vida.

Vale salientar ainda que o consumismo exacerbado das sociedades modernas contribuiu ainda mais para a depredação do bioma natural, toda essa cultura de bens de consumo é exaltado pelo atual modelo econômico, na qual os produtos se tornaram descartáveis, mostrando a população que o que é bom é aquele produto novo, fazendo a mesma consumir mais sem necessidade, gerando assim mais lixo e mais desgaste natural, já que se precisará produzir mais.

\footnotetext{
Além disso, o maior bem-estar das pessoas não é diretamente proporcional à maior quantidade de bens que consomem. $\mathrm{O}$ atual modelo econômico estimula um consumo crescente e irresponsável de bens materiais, mas depara com a constatação de que há um limite para esse consumo que de fato condena a vida na Terra a uma rápida destruição (BRASIL, 2001, P.49).
}

Nesse sentido surgem vários questionamentos sobre esses modelos radicais de produção, o que atualmente, após várias conferências e encontros que debatam sobre esse assunto veio à tona a palavra sustentabilidade, ou desenvolvimento sustentável, essa, nada mais é de que utilizar os recursos naturais: renováveis e não-renováveis de maneira equilibrada, sem comprometer o futuro das gerações futuras. O desenvolvimento sustentável foi definido pela Comissão Mundial sobre Meio Ambiente e Desenvolvimento. 
Nas propostas apresentadas pelo Programa das Nações Unidas para o meio Ambiente (Pnuma), emprega-se o termo "desenvolvimento sustentável” significando "melhorar a qualidade da vida humana dentro dos limites da capacidade de suporte dos ecossistemas." Isso implica, entre outros requisitos, o uso sustentável dos recursos renováveis, ou seja, de forma qualitativamente adequada e em quantidades compatíveis com sua capacidade de renovação (BRASIL, 2001, P. 38-39).

Precisa-se mais engajamento de toda a sociedade brasileira e mundial para que se amenize o esgotamento dos recursos naturais, vale lembrar também que além da escola como forte entidade formadora de opinião, a mídia também desempenha esse papel de construir e desconstruir formas de pensar, fazendo com que a população modifique suas atitudes e possam reavaliar suas práticas pessoais em relação a conservação e vitalidade da diversidade ecológica do planeta Terra.

Dessa forma o desenvolvimento sustentável parte da ideia de que as ações humanas sejam norteadas dentro de técnicas e princípios de conservação ambiental, a fim de que essa sociedade "sustentável" que tanto se almeja possa se tornar realidade, em busca de uma melhor qualidade de vida humana e a todo o ecossistema.

\section{Justificativa}

Justifica-se esse trabalho ao perceber que a educação ambiental deve ser trabalhada cotidianamente nos ambientes escolares, tema de grande necessidade de aquisição de conhecimentos e informação para que os discentes possam multiplicar essa ideia no seio familiar, na comunidade vivente e na sociedade, então esse enfoque interdisciplinar, unir os gêneros textuais de Língua Portuguesa com um breve referencial teórico sobre a educação ambiental promove a participação dos alunos nas experiências construídas por eles tanto no âmbito escolar como no extraescolar.

Em (BRASIL, 2001, p.47-48), 
Id on Line Revista Multidisciplinar e de Psicologia

Id on Line Multidisciplinary and Psycology Journal

ligações entre o que aprende e o que já conhece, e também da possibilidade de utilizar o conhecimento em outras situações.

Além disso é de grande importância para o professor favorecer ao aluno a criticidade, tanto referente ao tema meio ambiente, quanto aos demais temas transversais e diversos outros. Em relação ao meio ambiente vale salientar que o aluno precisa se questionar sobre bem-estar, saúde, proteção, conservação e vitalidade do planeta.

O convívio escolar é um fator determinante para ser desenvolvido essas questões, já que o aluno permanece no mínimo quatro horas do tempo dele nesse ambiente. É na escola que a criança é fomentada a decidir problemas do próprio cotidiano, com isso os docentes precisam aproveitar em suas praticas diárias a trabalhar uma questão de urgência, o meio ambiente.

\section{Metodologia}

Para ser desenvolvido esse trabalho, a interdisciplinaridade entre a educação ambiental e os gêneros textuais houve um estudo mais aprofundado dos tipos de testos e gêneros durante o ano letivo de 2015 em uma turma de $7^{\circ}$ Ano de uma escola pública municipal de Juazeiro do Norte-Ce. Sabe-se que atualmente a tipologia textual e os gêneros textuais se tornaram frequentes nas aulas de Língua Portuguesa, sendo uma excelente oportunidade de trabalhar e discutir a língua nos mais diversos usos do cotidiano, assim, após o estudo dos gêneros textuais vistos durante os dois semestres nessa série, abordou-se para uma questão que se discute diariamente, o meio ambiente.

A partir desse tema foi levada à proposta aos discentes, os mesmos iriam elaborar um a produção textual baseada em um dos gêneros abordados nas aulas com o tema meio ambiente. Durante o mês que se trabalhou a proposta da produção textual, o docente mostrou através de vídeos, revistas livros e discussões em sala sobre como o meio ambiente está sendo desgastado muito e rapidamente.

Nesse período foi apresentado também diversos subtemas relacionados ao tema meio ambiente, como: A poluição da água, o lixo se acumula na cidade, a poluição atmosférica, resíduos sólidos, aquecimento global, a tecnologia e o meio ambiente, o desmatamento e as 
Id on Line Revista Multidisciplinar e de Psicoloqia

Id on Line Multidisciplinary and Psycology Journal

consequências para a humanidade, poluição das praias, a extinção de animais dentre vários outros. O resultado dessa pesquisa foi bastante satisfatório, pois os discentes usaram de sua criatividade realizando a proposta teórica em produções textuais excelentes, nas quais haverá uma amostragem de algumas em anexos.

Salienta-se por fim que ainda é necessário que os docentes se utilizem dessa prática para que as aulas se ampliem para novas abordagens e se tornem assim mais atrativas, o que resultará em mais pesquisas, leitura, envolvimento com a turma, aprendizagem, que é o objetivo essencial em uma escola e acima de tudo mudanças de atitude e criticidade diante de questões que merecem atenção da sociedade.

\section{Considerações Finais}

Apoiando-se na proposta do ensino dos gêneros textuais em sala de aula, na qual se obteve resultados satisfatórios , que foi trabalhado a produção textual com alunos do Ensino Fundamental II, $7^{\circ}$ Ano, com um tema relevante, o meio ambiente fez com que os discentes se conscientizassem ainda mais sobre as atitudes dos mesmos e da sociedade em ralação a essa temática. Essa abordagem surgiu como uma necessidade de repensar o que se está fazendo para que se possa usufruir um pouco mais da natureza, sem essa é impossível haver vida no Planeta.

Nesse estudo houve também uma preocupação em se trabalhar uma das disciplinas transversais, já que os parâmetros curriculares nacionais (PCN'S) abordam a integração entre as áreas do saber, então, como o meio ambiente é uma disciplina que precisa ser dada uma atenção especial, por se estar tratando também da permanência de humanos, vegetais e animais na terra, surgiu a adequação ou a união do estudo do meio ambiente sob a ótica dos gêneros textuais.

Os PCN'S afirmam (1998:193) que quando se trabalha de forma transversal se busca a transformação de conceitos, mostrando a realidade da sociedade no cotidiano. Isso só mostra como é eficaz interligar as áreas de conhecimento, uma "conversa" com a outra, de modo que se estabeleça uma visão mais ampla dos conhecimentos acumulados pela humanidade. 
Id on Line Revista Multidisciplinar e de Psicoloqia

Id on Line Multidisciplinary and Psycology Journal

Sabe-se que quando se restringe ou se aborda apenas a área especifica do professor, torna-se mais inacessível outros conteúdos, vivências e aprendizagens. Deve-se portanto aglutinar as diversas áreas do conhecimento com o objetivo de proporcionar e desenvolver a capacidade dos discentes de intervir com criticidade a realidade, transformando-a para a melhoria das condições de vida.

\section{Referências}

BRASIL. Parâmetros Curriculares Nacionais: terceiro e quarto ciclos: Apresentação dos temas transversais. Secretaria de Educação Fundamental. Brasília: MEC/SEF, 1998.

BRASIL, Parâmetros Curriculares Nacionais: Meio Ambiente: Saúde/ Ministério da Educação. Secretaria de Educação Fundamental. $3^{\text {a }}$ Ed. Brasília: A Secretaria, 2001.

KLEIMAN, Angêla B. e MORAES, Silva. Leitura e Interdisciplinaridade: Tecendo redes nos projetos da escola. Campinas: Mercado de Letras, 1999.

MACHADO, Nilson José. Epistemologia e didática: As concepções de conhecimento e a inteligência e a prática docente/Nilson J. Machado. $7^{a}$ Ed. São Paulo, Cortez, 2011.

MARCUSCHI, Luís Antônio. Gêneros textuais: Definição e funcionalidade. In: DIONISIO, A. P. ; MACHADO, A. R. ; BEZERRA, M.A. (orgs.) Gêneros textuais e ensino. $4^{\text {a }}$ Ed. Rio de Janeiro. Editora Lucerna, 2002.

MARCHUSCHI, Luís Antônio. Produção de textos, análise de gêneros e compreensão. São Paulo: Parábola Editorial, 2008.

MATTA, Sozângela Shemim da. Português: Linguagem e interação. Curitiba: Bolsa nacional do livro Ltda. 2009.

PORTO, Marcia. Um diálogo entre os gêneros textuais. Curitiba: Aymará, 2009.

\section{Como citar este artigo (Formato ABNT):}

OLIVEIRA, M.C..L. Educação ambiental e os gêneros textuais. Id on Line Revista Multidisciplinar e de Psicologia, Out-Nov. de 2016, vol.10, n.31, Supl 3, p. 100-111. ISSN 1981-1179. 